\title{
A PARAMETRIC EXPLORATION OF SUPERSONIC BUSINESS JET CONCEPTS UTILIZING RESPONSE SURFACES
}

\author{
Aerospace Systems Design Laboratory \\ School of Aerospace Engineering \\ Georgia Institute of Technology \\ Atlanta, Georgia 30332-0150
}

Simón I. Briceño*, Michael A. Buonanno*, Ismael Fernández*, and Dimitri N. Mavrisł

\begin{abstract}
Market forecasts predict a potentially large market for a quiet supersonic business jet provided that several technical hurdles are overcome prior to fielding such a vehicle. In order to be acceptable, the QSJ must be able to fly at supersonic speeds over land and operate from regional airports while meeting government noise and emissions requirements. Physics based analysis tools are used in conjunction with a Response Surface metamodeling approach to create an environment in which the performance, economics, and environmental impact of the aircraft can be studied as a function of design and mission parameters. Through the use of this environment, the designer is able to rapidly explore the entire concept space by dynamically modifying the configuration, engine cycle, and requirements. Results obtained using this exploration tool indicate that it may be possible to meet emissions and noise requirements, but that technology infusion will be required in order to meet all performance and economic goals. Finally, this same physics-based environment was used to assess the impact of a portfolio of technologies on the system's acceptability.
\end{abstract}

\section{INTRODUCTION}

Development of the first supersonic commercial aircraft started in the early 1960's with the collaboration of the British and French in developing the Concorde, which took its maiden flight in 1967; however, many disturbing constraints emerged despite the optimism shown by British investors in the early stages of the aircraft's development. The excessive takeoff noise and sonic boom of the Concorde created a highly restrictive operational market space where the aircraft is prohibited from supersonic flight overland and serviceable only from a handful of coastal airports. After the failure of the

\footnotetext{
* Graduate Research Assistant, School of Aerospace Engineering, Student Member, AIAA.

† Boeing Chair for Advanced Design, School of Aerospace, Director, ASDL, Associate Fellow, AIAA

Copyright (C) 2001 by Briceño, Buonanno, Fernández, and Mavris. Published by the American Institute of Aeronautics and Astronautics, Inc. with permission.
}

HSCT program in the mid 1990's, the platform of choice for the next generation of commercial supersonics became the supersonic business jet. This shift was a result of the lower economic sensitivity of business aircraft as well as the much lower system weight. This class of vehicle is particularly appealing to executives that can afford to pay a premium for fast transportation, but it would also be useful for medical evacuation, airfreight, and military applications. Because of increasing environmental awareness, the focus for the design of this aircraft must include environmental concerns in addition to traditional performance and economic metrics. The aircraft must be able to fly overland at supersonic speeds with minimum sonic boom, and the engine must meet or improve on noise and emissions requirements. In this study, it was found that a combination of seven technologies working synergistically could yield an answer that best approaches the ideal solution according to an established evaluation criterion. Among these potentially beneficial technologies are new concepts addressing combustion, materials and noise reduction. One of the most important constraints, the sonic boom, is not specifically addressed by any of the technologies in the portfolio, however, and other concepts and configurations should be studied to minimize the impact of the sonic boom on the ground observer. The results indicate that further market research is needed to confirm and evaluate the willingness of the customer to trade between performance, price and delivery date.

\section{TECHNICAL APPROACH}

In order to capture the significance of requirements and aircraft configuration in the early definition phases of the design process, a mathematical model that relates the system level attributes to the requirements and configuration factors is needed. A response surfacebased metamodeling approach ${ }^{1}$ is used as this model in conjunction with physics-based analysis tools such as FLOPS $^{2}, \mathrm{AERO}^{3} \mathrm{~S}^{3}$, and NEPP ${ }^{4}$. The result is a parameterized tradeoff environment in which attributes governing the system's feasibility and viability can be rapidly calculated as a function of aircraft's configuration and system's requirements. 
RSM is a mathematical modeling technique that approximates the behavior of a response (such as a disciplinary or system level metric) as a function of design parameters through a specific polynomial function, known as Response Surface Equation (RSE). As shown below, this representation usually includes linear, quadratic, and interaction terms between the design parameters:

$$
R=b_{o}+\sum_{i=1}^{n} b_{i} x_{i}+\sum_{i=1}^{n} b_{i i} x_{i}^{2}+\sum_{i=1}^{n-1} \sum_{j=i+1}^{n} b_{i j} x_{i} x_{j}
$$

where:

$R=$ response of interest

$x_{i}, x_{j}=$ design variables

$b_{i}=$ regression coefficients for linear terms

$b_{i i}=$ regression coefficients for pure quadratic terms

$b_{i j}=$ regression coefficient for interaction terms

The steps in the RSM process are:

i. Selecting design variables and their ranges

ii. Screening test via an Analysis of Variance (ANOVA) using the results from the execution of a 2-level Design of Experiments

iii. Selecting an appropriate Design of Experiments for the number of significant factors and number of simulation cases

iv. Running the prescribed simulation cases and collecting the appropriate response data

v. Performing multivariate regression analysis to build the RSEs

vi. Validating the model via a confirmation test and random sample of cases

Once the experiment is selected, appropriate ranges for the design variables must be determined. After performing the experiments and gathering the output data, a statistical analysis package is used to perform a least squares multiple linear regression to determine the RSE coefficients. The RSE's negligible computational time allows the user to perform rapid optimization, Monte Carlo Simulation, or concept exploration.

\section{DESIGN AND REQUIREMENTS SPACE DEFINITION}

By using an Integrated Product and Process Development (IPPD) approach early in the study, it was established that both traditional design parameters such as degrees of wing sweep or overall pressure ratio along with mission design parameters such as cruise Mach number would be vital in determining system feasibility and viability. The critical technological obstacle in the path of QSJ development was determined to be sonic boom reduction, though emissions, field performance, airport noise, and economics were also found to be constraining factors. This prompted a multi-disciplinary approach to the problem in which RSM was used to give the design team a visual representation of the concept space and the ability to perform rapid tradeoffs between constraining factors rather than just perform an optimization to maximize a specified composite Overall Evaluation Criterion.

To determine the baseline aircraft around which the concept space exploration would take place, a Quality Function Deployment tool was used coupled with a Morphological Matrix (Figure 1). Though several potentially advantageous configurations such as a Parasol or Joined-Wing configuration were identified as having favorable attributes, a rather conventional baseline aircraft was selected for demonstration purposes due to the availability of data on similar configurations. This data allowed the design team to compare the performance and weight metrics generated by the design environment with those generated by other teams studying similar configurations.

\begin{tabular}{|c|c|c|c|c|c|}
\hline \multicolumn{2}{|c|}{ Attributes } & Alt 1 & Alt 2 & Alt 3 & Alt 4 \\
\hline \multirow{4}{*}{ Config } & Vehicle & Wing \& Tail & Wing \& Canard & Wing, Tail \& Canard & Flying Wing \\
\hline & Planform & Conventional & Double Delta & Parasol & Joined Wing \\
\hline & Fuselage & Cylindrical & Oval & Area Ruled & \\
\hline & Avionics & Standard & Advanced & Synthetic V. & \\
\hline \multirow{3}{*}{ Mission } & Range (nm) & 4000 & 4500 & 5000 & 5500 \\
\hline & Cruise Mach & 1.4 & 1.6 & 1.8 & 2 \\
\hline & Passengers & 6 & 8 & 10 & 12 \\
\hline \multirow{6}{*}{ Propulsion } & Engine Type & Turbojet & Turbofan & Flade & \begin{tabular}{|l} 
Mid-tandem Fan \\
\end{tabular} \\
\hline & \# Engines & 2 & 3 & & \\
\hline & Engine Position & Under Wings & Aft Fuselage & Over Wing & Inside Wing \\
\hline & Intake & Fixed Conical & Rectangular & Variable shape & \\
\hline & Combustor & Conventional & $\begin{array}{c}\text { Active Combustion } \\
\text { Control }\end{array}$ & RQL & LPP \\
\hline & Nozzle & Separate Flow & Mixer & Variable Geometry & Thrust Vectoring \\
\hline \multirow{2}{*}{ Structure } & Materials & Aluminum & Titanium & Composites & Super Alloys \\
\hline & Process & Integrally Stiffened & Spanwise Stiffened & Monocoque & Hybrid \\
\hline \multirow{2}{*}{ Aero } & Low Speed & \begin{tabular}{|l} 
Conventional Flaps \\
\end{tabular} & C.F. + Slots & & \\
\hline & High Speed & Conventional & NLFC & Active Control & HLFC \\
\hline
\end{tabular}

Figure 1 - Morphological Matrix (with selected baseline shaded)

Once the baseline aircraft ( Figure 2) and engine (Figure 3 ) were selected, the design team used brainstorming techniques in conjunction with IPPD to determine the parameters that this team felt had the largest impact on the selected baseline system. After selecting these parameters (Table 1) research was performed to determine appropriate ranges by using physics and historical data, along with trial and error.



Figure 2 - Baseline Design 


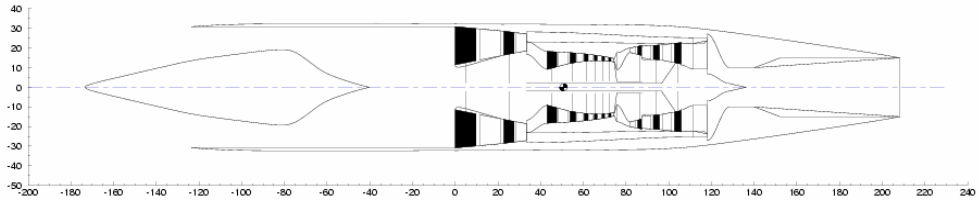

Figure 3 - Baseline Engine Design

Though most of the design parameters are selfexplanatory, several require clarification. The four strake intersection variables define the kink points in the wing planform referenced to percent fuselage length in the case of Strake-Body Intersection or percent span for Strake-Wing Intersection (Figure 12).

\begin{tabular}{|c|c|c|c|}
\hline Type & Variable & Min & Max \\
\hline \multirow{4}{*}{ 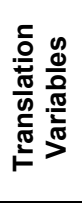 } & Engine Location (ft) & 100 & 110 \\
\hline & Wing Location (ft) & 45 & 57 \\
\hline & Cabin Location (ft) & 36 & 41 \\
\hline & Empennage Location (ft) & 87 & 97 \\
\hline \multirow{2}{*}{ 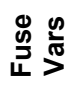 } & Cabin Length $(\mathrm{ft})$ & 39 & 50 \\
\hline & Fuselage Length (ft) & 135 & 160 \\
\hline \multirow{12}{*}{ 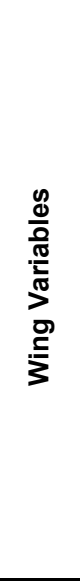 } & Aspect Ratio & 2 & 2.5 \\
\hline & Taper Ratio & 0.05 & 0.3 \\
\hline & Planform Area $\left(\mathrm{ft}^{2}\right)$ & 2300 & 3100 \\
\hline & Wing Sweep & 67 & 74 \\
\hline & Strake-Body Intersection & 0.4 & 0.8 \\
\hline & Strake-Wing Intersection & 0.2 & 0.4 \\
\hline & Aft Strake- Body Int. & 0.4 & 0.6 \\
\hline & Aft Strake-Wing Int. & 0.2 & 0.5 \\
\hline & Root Thickness/Chord & 0.025 & 0.045 \\
\hline & Tip Thickness/Chord & 0.025 & 0.035 \\
\hline & Root Twist $\left({ }^{\circ}\right)$ & -2 & 2 \\
\hline & Tip Twist $\left({ }^{\circ}\right)$ & 0 & 5 \\
\hline \multirow{6}{*}{ 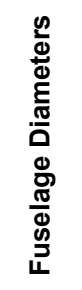 } & Diameter $1(\mathrm{ft})$ & 2.2 & 3 \\
\hline & Diameter $2(\mathrm{ft})$ & 7.2 & 7.6 \\
\hline & Diameter $3(\mathrm{ft})$ & 7.2 & 8 \\
\hline & Diameter $4(\mathrm{ft})$ & 7.2 & 7.6 \\
\hline & Diameter $5(\mathrm{ft})$ & 4.5 & 6.5 \\
\hline & Diameter $6(\mathrm{ft})$ & 2.3 & 3.1 \\
\hline \multirow{4}{*}{ 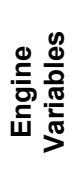 } & Overall Pressure Ratio & 22 & 29 \\
\hline & Turbine Inlet Temp ( $\left.{ }^{\circ} \mathrm{R}\right)$ & 3300 & 3400 \\
\hline & Fan Pressure Ratio & 2.6 & 3.2 \\
\hline & Throttle Ratio & 1.2 & 1.23 \\
\hline \multirow{7}{*}{ 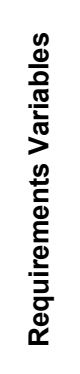 } & Aircraft Thrust/Weight ratio & 0.41 & 0.45 \\
\hline & Number of Passengers & 8 & 12 \\
\hline & $\begin{array}{l}\text { Manuf. Return on } \\
\text { Investment }\end{array}$ & 6 & 12 \\
\hline & $\begin{array}{c}\text { Number of Vehicles } \\
\text { Produced }\end{array}$ & 200 & 500 \\
\hline & Design Range (nm) & 3500 & 4200 \\
\hline & Design Mach Number & 1.6 & 1.8 \\
\hline & Takeoff Thrust Derating & 0.8 & 1 \\
\hline
\end{tabular}

Table 1 - Design Variables and Ranges
Since AWAVE's internal optimizer is not used, six critical fuselage diameters (Figure 12) have been selected as design variables and assigned ranges so that passenger comfort or structural constraints would not be violated.

\section{CONFIGURATION AND CYCLE ANALYSIS}

In order to calculate the large number of performance, environmental, and economic metrics essential for evaluation of system feasibility and viability, a total of ten disciplinary codes (depicted as a Design Structure Matrix in Figure 4) along with numerous custom made computer programs were linked together using the commercially available process integration tool iSIGHT. This integrated environment proved to be quite time consuming to build and debug because of both the large number of variables that need to be passed from one code to another and also the different input formats required by each of the disciplinary codes. Initially, it was attempted to integrate a custom-made stability analysis program to calculate the aircraft's center of gravity and its center of lift as a function of Mach number where the resulting information was used to find required tail trim force and the resulting trim drag. This program is not used in the final analysis suite, however, because the excessive trim drag of many other configurations caused the design codes to crash.



Figure 4 - Design Structure Matrix

Rapid Aircraft Modeler (RAM) is used to generate an aircraft geometry file as a function of the input design variables. The configuration's drag polar is then determined by using three separate aerodynamic analysis programs $\left(V^{2} \mathrm{RLAX}{ }^{18}, \mathrm{AWAVE}^{19}\right.$ and $\mathrm{BDAP}^{20}$ ) to solve for the aircraft's induced, wave and skin friction drag respectively. Detailed low speed induced drag calculations are also performed using AERO2S, which is capable of calculating the influence of leading- and trailing-edge flaps.

There are two main codes used for engine analysis, NEPP $^{4}$ and WATE $^{5}$. NEPP (NASA Engine Performance 
Program) is a NASA and propulsion industry developed program that analyzes the one-dimensional, aero- and thermodynamic characteristic of the flow going through the engine. NEPP simulates an engine by defining basic engine components and allowing the user to "link" them together to form a complete engine. The user is able to further define each engine component as well as its operational points, and NEPP will integrate all of the components to form an engine cycle. Based on these inputs, NEPP will estimate/predict the performance of the engine in the form of an engine deck as well as the flow properties (i.e. mass flow, pressure, and temperature) at each engine station.

In addition to the thermodynamic analysis, an estimation of the weight and physical properties of the engine must be determined. The program used for this purpose, WATE (Weight Analysis of Turbine Engines), is also a NASA developed program which predicts the flow path as well as the weight and envelope dimensions of large and small gas turbine engines. WATE is able to predict these results based on the cycle analysis output from NEPP as well as a combination of correlation and preliminary design procedures that are sensitive to blade geometry, operating conditions, material properties, shaft speed, hub-tip ratio, etc. The weight estimate provided by WATE is a conservative one since the program performs a bubble search through the entire user-defined flight envelope to determine the most critical condition for each engine component.

In order to obtain useful mission data, a mission sizing and synthesis code must be employed that can generate responses such as Take-Off Gross Weight (TOGW), landing and takeoff field lengths, etc. To compute these parameters flight optimization code (FLOPS ${ }^{2}$ ) is used. FLOPS is a multidisciplinary system of computer programs for the conceptual and preliminary design and evaluation of advanced aircraft concepts. It consists of nine primary modules, including weights, mission performance, takeoff and landing, noise footprint, and program control. The noise analysis carried out in this investigation, including FAR sideline and flyover noise calculations, is performed by a modified version of FOOTPR integrated into FLOPS under the name NOISIN. Once the aircraft has been sized, a feedback loop ensures that the correct nacelle geometry was used to calculate the aircraft's drag polar.

Once the aircraft is sized, PBOOM ${ }^{15}$ calculates the sonic boom signature of the aircraft. This program combines several other aerodynamic and acoustic analysis tools and allows the user to determine the overpressure associated with both level and maneuvering flight under a wide range of flight conditions. The program uses the linear theory developed by Whitham and others in its analysis by computing the effective cross-sectional area of the configuration that consists primarily of the sum of the volume of the body and the equivalent volume due to lift. The program then uses the calculated equivalent area along with the Whitham F-function to calculate the pressure signature due to the formation of shock waves. A user selected propagation model transmits the calculated near field pressure signature through the atmosphere to the ground and outputs the pressure overpressure felt by the ground observer as a function of both time and distance. If interested, the reader is referred to Reference 16 for a detailed description of linear sonic boom theory.

Finally, the Aircraft Life Cycle Cost Analysis (ALCCA ${ }^{6}$ ) code is used to estimate the acquisition, operating, and other life cycle costs associated with purchasing and operating an aircraft. It uses a historical database along with input component weights and other aircraft characteristics such as expected Return on Investment for its cashflow analysis calculations.

\section{METRIC SELECTION}

The results of the Quality Function Deployment analysis along with market research performed by members of industry were used to select eleven key performance, economic, and environmental targets (Table 2).

\begin{tabular}{|l|c|}
\hline & Constraint Value \\
\hline Take-Off Gross Weight (lbs) & 125000 \\
\hline Take-Off Field Length (ft) & 6500 \\
\hline Approach Speed (kts) & 130 \\
\hline CO2 emissions (lb/nm) & 50 \\
\hline NOx emissions (\% below 2004 ICAO rule) & $0 \%$ \\
\hline Sideline Noise (dB) & 92 \\
\hline Flyover Noise (dB) & 88 \\
\hline Initial Shock Overpressure (psf) & 0.5 \\
\hline Sonic Boom Impulse (lb*s/ft ${ }^{2}$ ) & 0.02 \\
\hline Acquisition Price (2002 \$) & 100 \\
\hline Direct Operating Costs (2002 \$/NM) & 6 \\
\hline
\end{tabular}

Table 2- Metrics and Targets

This research indicates that each of these constraint values must be met or improved upon in order for a vehicle to be acceptable to both its customers and to government regulators. Greater detail on the definition of each of these metrics is found in References 21-23.

\section{CONCEPT SPACE EXPLORATION}

RSM was used to find the influence of each of the design variables on the chosen figures of merit after determining the metrics to track and creating the physics-based environment,. One thousand twenty-five separate configurations were analyzed and the statistics package JMP® was used to solve for the required response surface coefficients.

The generated response surfaces were then used to create a dynamic design space exploration tool called a prediction profiler (Figure 13). Through the use of this tool, the engineer can determine visually the impact of each variable on the chosen response, and calculate these response values in real time. 


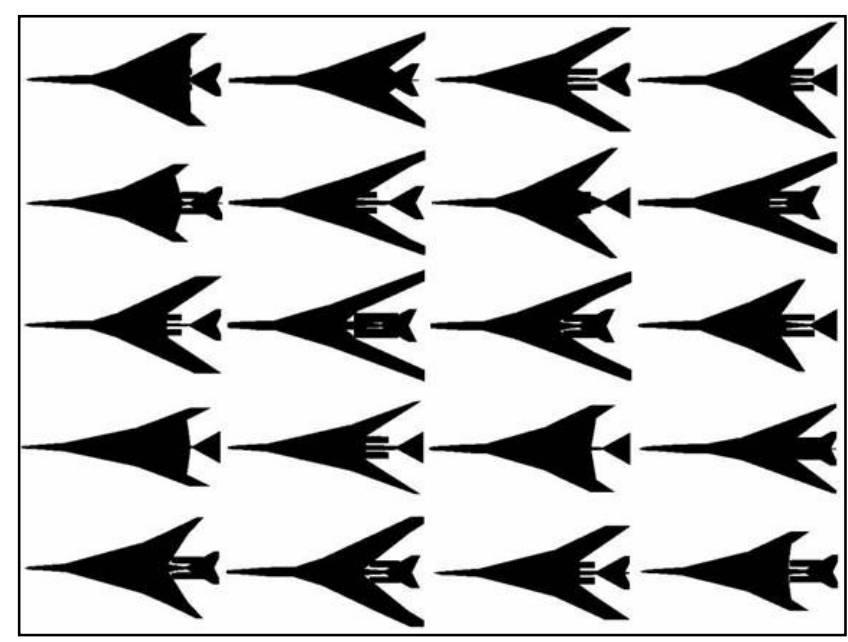

Figure 5 - Sample Planforms from the Design of Experiments (20 out of 1025)

The negligible computational expense associated with evaluating a response surface enables the use of Monte Carlo simulation to locate feasible design space. After assigning uniform distributions over the specified ranges for each of the input parameters, thousands of function evaluations were performed and the data was collected and presented as a cumulative distribution function. The results of this analysis indicates that eight of the eleven established constraints can be met by concepts in the design space, but that the criteria for Take Off Gross Weight, Direct Operating Cost, and Initial Overpressure cannot (Figure 6).

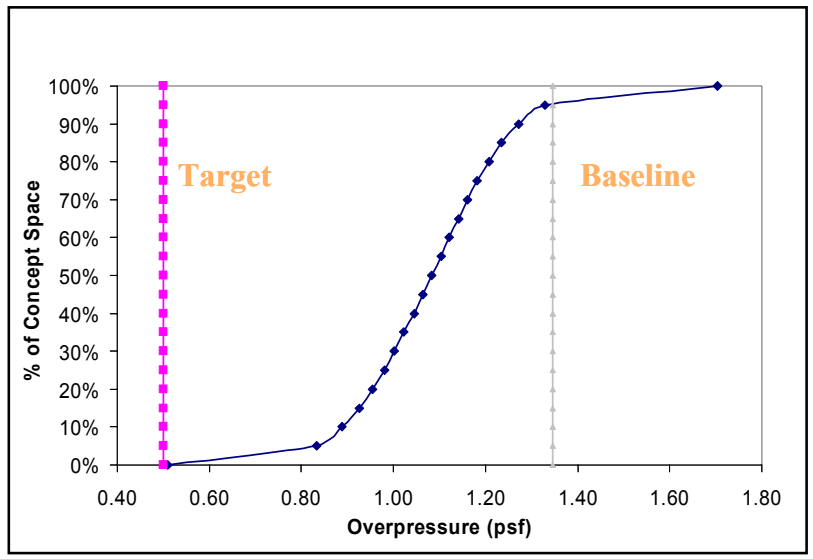

Figure 6 - Initial Overpressure Cumulative Distribution Function

Even though Monte Carlo simulation indicated that there was no feasible design space, optimization using sequential quadratic programming was performed using the constraints listed in Table 2. As expected, a feasible design is not achievable, but the configuration closest to this feasibility was identified and selected (Figure 7).

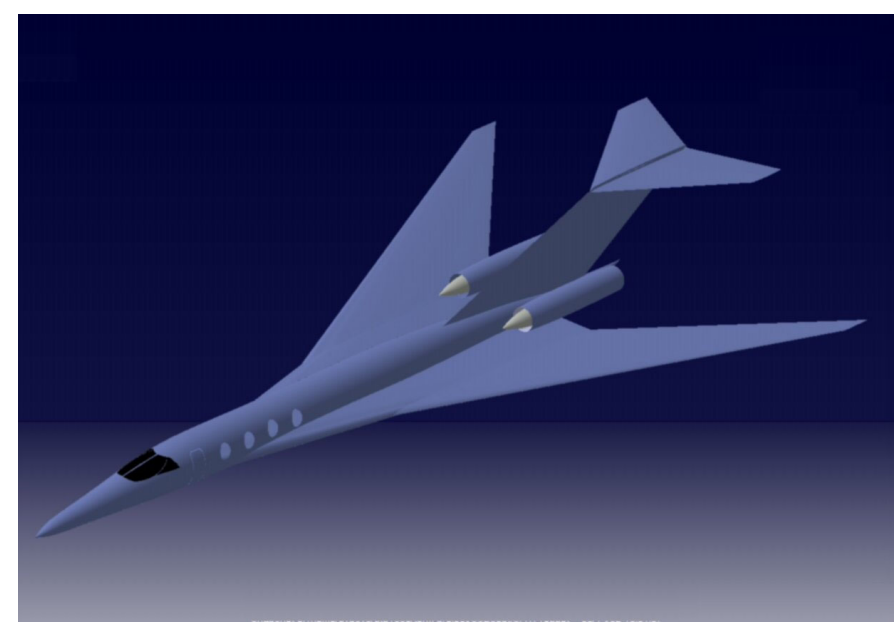

Figure 7 - Optimized Design

The optimized results (Table 3 ) indicate that this new configuration violates a total of four constraints, though two of the metrics (TOGW and Approach Velocity) are very close to feasibility, and could probably be met via slight requirements relaxation or design space expansion. The other two violated constraints (Initial Overpressure and Direct Operating Costs) will likely require either technology infusion or new concept selection in order to meet the program's goals.

\begin{tabular}{|l|c|c|}
\hline & Constraint & Optimized Value \\
\hline Take-Off Gross Weight (Ibs) & 125000 & 125381 \\
\hline Take-Off Field Length (ft) & 6500 & 6409 \\
\hline Approach Speed (kts) & 130 & 134.392 \\
\hline CO2 emissions (Ib/nm) & 50 & 42.34 \\
\hline NOx emissions (\% below 2004 ICAO rule) & $0 \%$ & $-38 \%$ \\
\hline Sideline Noise (dB) & 92 & 99.5 \\
\hline Flyover Noise (dB) & 88 & 93 \\
\hline Initial Shock Overpressure (psf) & 0.5 & 0.6818 \\
\hline Sonic Boom Impulse (lb*s/ft $\left.{ }^{2}\right)$ & 0.02 & 0.01645 \\
\hline Acquisition Price (2002 \$) & 100 & 97.62 \\
\hline Direct Operating Costs (2002 \$/NM) & 6 & 7.04 \\
\hline
\end{tabular}

Table 3 - Optimized Values

\section{TECHNOLOGY INFUSION}

Design space exploration revealed that the feasibility criteria are not met by any concept within the space. The two largest performance gaps between the best achievable performance and the constraints exist in the areas of sonic boom impact and aircraft economics. Ideally, research would focus on technologies that address these issues but since the technology evaluation study was performed concurrently with design space exploration due to time restrictions this knowledge was not available. Accordingly, thirteen technologies were selected by using the QFD results and information on them was gathered by using publicly available information.

\section{TECHNOLOGY IDENTIFICATION}

The technologies described here fall into three main categories: Airframe, Propulsion and Aircraft Systems. 
$\underline{\text { Technology 1: Stitched Composites }}$

These composite components will blend together on the wing structure, eliminating the need for mechanical fasteners. This results in a major reduction in both weight in and cost of materials and manufacturing.

\section{$\underline{\text { Technology 2: Super-Alloys AL-LI }}$}

This Light Weight Alloy, with the addition of Silicon Carbide, forms a Metal Matrix Composite with reduced weight and superior performance and strength.

\section{Technology 3: Super-Plastic Forming}

This net-shape processing technology dramatically reduces fabrication and assembly costs by reducing the number of parts and assembly time.

$\underline{\text { Technology 4: Airframe Manufacturing Methods }}$

Several technologies included in this program including Low Cost Composite Manufacturing Methods, High Speed Machining and Resin Transfer Molding enhance the quality of manufacturing thereby reducing maintenance cost.

\section{Technology 5: Separation Flow Control}

This technology increases the lift coefficient on takeoff without degrading the performance of the engines by using electromagnetic forces.

Technology 6: Rich Burn, Quick Quench, Lean Burn $\underline{(R Q L)}$

The RQL process reduces $\mathrm{NO}_{x}$ emissions by using multi-staged combustion. In the first stage, the combustion process takes place under fuel-rich or low oxygen conditions therefore inhibiting the formation of $\mathrm{NO}_{x}$.

Technology 7: Lean Burn, Pre-mixed, Pre-vaporized $\underline{(\mathrm{LPP})}$

The LPP combustor prevaporizes the fuel and injects it into the air in a premixing passage to deliver a uniform droplet-free mixture to the combustion zone. $\mathrm{NO}_{\mathrm{x}}$ reduction is also the objective of this technology.

\section{Technology 8: Ceramic Matrix Composites (CMC)}

Turbine components made with CMCs allow higher material temperatures, resulting in higher thrust or lower required turbine cooling flow.

\section{$\underline{\text { Technology 9: Light Nozzle Materials }}$}

These advanced materials can either reduce nozzle weight or engine noise by allowing larger nozzles to be used with no weight penalty.
Technology 10: Active Combustion Control

Active Combustion Control improves the effectiveness of RQL and LPP and controls the efficiency and the emissions of the combustor based on feedback from sensors placed on turbine blades.

\section{Technology 11: Environmental Engine}

This technology represents the successful results of the Integrated High Performance Turbine Engine Technology (IHPTET) program. The project benefits of this family of technologies include reduced emissions, engine noise and weight.

\section{$\underline{\text { Technology 12: Avionics Systems }}$}

These new materials and designs allow antennas to be embedded in the structure, thereby reducing drag and increasing performance.

\section{Technology 13: Advanced Control Systems}

This set of two technologies improves the aircraft's handling characteristics and decreases the fatigue suffered by the control surfaces by using Active Load Alleviation and Directional Nozzles.

\section{$\underline{\text { TIM AND TCM }}$}

The Technology Compatibility Matrix or TCM is shown in Figure 8 . It summarizes the incompatibilities among the technologies considered for infusion. Incompatible relationships are indicated by a zero. The Technology Readiness Level or TRL is a number that specifies the grade of maturity of a given technology. A TRL number of 1 represents a new concept or theory, while a TRL of 9 means the technology is currently used in a production vehicle.

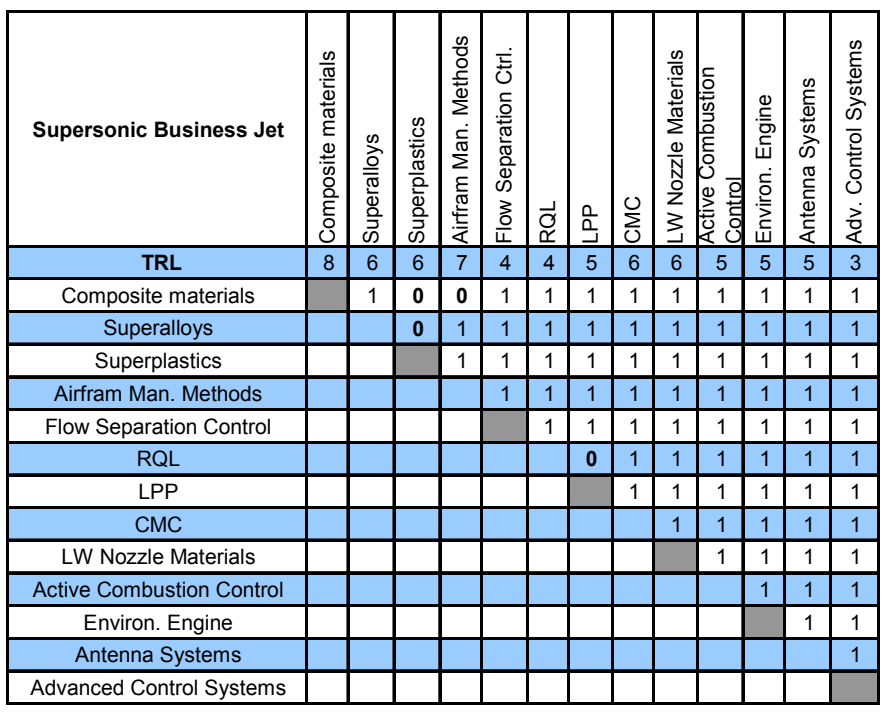

Figure 8 - Technology Compatibility Matrix 


\begin{tabular}{|c|c|c|c|c|c|c|c|c|c|c|c|c|c|c|c|c|}
\hline & & \multicolumn{13}{|c|}{ Technologies } & & \\
\hline & $\begin{array}{l}\frac{\frac{\text { Supersonic }}{\text { Business Jet }}}{\text { Technology Impact }} \\
\text { Matrix }\end{array}$ & 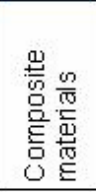 &  & 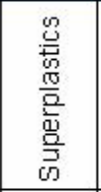 & 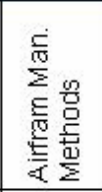 & 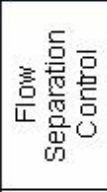 & $\frac{\overrightarrow{0}}{\alpha}$ & 号 & $\sum_{0}^{\cup}$ & 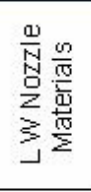 &  & 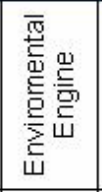 & 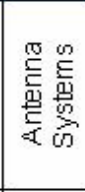 & 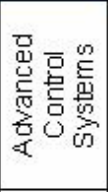 & \multicolumn{2}{|c|}{$\begin{array}{c}\text { Hon-Dimensionalized } \\
\text { Impact }\end{array}$} \\
\hline & TRL & 8 & 6 & 6 & 7 & 4 & 4 & 5 & 6 & 6 & 5 & 5 & 5 & 3 & \begin{tabular}{|l|} 
Minimum \\
\end{tabular} & \begin{tabular}{|l|} 
Maximum \\
\end{tabular} \\
\hline & kfactor Name & $\mathrm{T} 1$ & $T 2$ & $T 3$ & T4 & 15 & $\pi$ & $\pi$ & 18 & $T$ & T10 & T11 & $\mathrm{T} 12$ & $T 13$ & & \\
\hline 1 & Wing Weight & $-20 \%$ & & $-10 \%$ & & $4 \%$ & & & & & & & & $1 \%$ & $-30.00 \%$ & $4.00 \%$ \\
\hline 2 & Fuselage Weight & & $-20 \%$ & & $-20 \%$ & $2 \%$ & & & & & & & & & $40.00 \%$ & $2.00 \%$ \\
\hline 3 & HTWeight & $-20 \%$ & & $-10 \%$ & $-20 \%$ & & & & & & & & & $2 \%$ & $-50.00 \%$ & $0.00 \%$ \\
\hline 4 & VTWeight & $-20 \%$ & & $-10 \%$ & $-20 \%$ & & & & & & & & & $2 \%$ & $-50.00 \%$ & $0.00 \%$ \\
\hline 5 & Engine Weight & & & & & & $-2 \%$ & $-2 \%$ & $-14 \%$ & $-2 \%$ & $2 \%$ & $-10 \%$ & & $10 \%$ & $-30.00 \%$ & $12.00 \%$ \\
\hline 6 & Hydraulics Weight & & & & & $2.00 \%$ & & & & & & & & $-2.00 \%$ & $-2.00 \%$ & $2.00 \%$ \\
\hline 7 & Noise & & & & & -1.00 & 0.50 & & -0.50 & -7.00 & -1.00 & 3.00 & & & $-27.00 \%$ & $6.00 \%$ \\
\hline 8 & Subsonic Drag & $-2.00 \%$ & & $-1.00 \%$ & & $2.00 \%$ & & & & & & & $-0.50 \%$ & $-1.00 \%$ & $-3.50 \%$ & $2.00 \%$ \\
\hline 9 & Supersonic Drag & $-4.00 \%$ & & $-2.00 \%$ & & $1.00 \%$ & & & & & & & $-1.00 \%$ & & $-7.00 \%$ & $1.00 \%$ \\
\hline 10 & Subsonic Fuel Flow & & & & & & $2.00 \%$ & $-2.00 \%$ & & & $-2.00 \%$ & $-10.00 \%$ & & & $-14.00 \%$ & $2.00 \%$ \\
\hline 11 & Supersonic Fuel Flow & & & & & & $2.00 \%$ & & & & $-2.00 \%$ & $-10.00 \%$ & & & $-12.00 \%$ & $2.00 \%$ \\
\hline 12 & CL@Takeoff & $2.00 \%$ & & & & $20.00 \%$ & & & & & & & & & $0.00 \%$ & $22.00 \%$ \\
\hline 13 & O\& S Cost & $-4.00 \%$ & & & $-20.00 \%$ & & $10.00 \%$ & $10.00 \%$ & $10.00 \%$ & & & $-12.00 \%$ & & $0.50 \%$ & $-36.00 \%$ & $30.00 \%$ \\
\hline 14 & RDT\&E Cost & $5.00 \%$ & $10.00 \%$ & & & $20.00 \%$ & $12.00 \%$ & $8.00 \%$ & $10.00 \%$ & $7.00 \%$ & $10.00 \%$ & $20.00 \%$ & $2.00 \%$ & $10.00 \%$ & $0.00 \%$ & $114.00 \%$ \\
\hline 15 & Production Cost & $-10.00 \%$ & $5.00 \%$ & $-10.00 \%$ & $-10.00 \%$ & $4.00 \%$ & $0.50 \%$ & $0.50 \%$ & $6.00 \%$ & $5.00 \%$ & $3.00 \%$ & $5.00 \%$ & $2.00 \%$ & $2.00 \%$ & $-30.00 \%$ & $31.00 \%$ \\
\hline 16 & Bleed air used to cool & & & & & & $-4.00 \%$ & $4.00 \%$ & $-30.00 \%$ & $1.00 \%$ & $5.00 \%$ & $6.00 \%$ & & & $-34.00 \%$ & $16.00 \%$ \\
\hline 17 & Nox Emissions & & & & & & $-10.00 \%$ & $-14.00 \%$ & $2.00 \%$ & $2.00 \%$ & $-1.00 \%$ & $\mid-10.00 \%$ & & $-2.00 \%$ & $-35.00 \%$ & $4.00 \%$ \\
\hline
\end{tabular}

Figure 9 - Technology Impact Matrix

The Technology Impact Matrix or TIM (Figure 9) summarizes the impact of each technology over the system. Each column represents a technology and each row represents an impact known as a $\mathrm{k}$ factor, or metric multiplier. Each technology is modeled mathematically by assigning it a vector of $\mathrm{k}$ factors that capture the costs and benefits associated with the given technology. The two columns on the right of the TIM indicate the maximum and minimum $\mathrm{k}$ factor possible with any combination of technologies, neglecting compatibility concerns.

\section{$\underline{\text { TECHNOLOGY EVALUATION PROCESS }}$}

The process of evaluating technologies starts with the selection of necessary $k$ factors. These inputs and their ranges are selected based on the information provided by the TIM. Scripts, which integrate all the analysis tools to create the simulation environment, take these inputs from the DoE and run the model to generate the responses.

The simulation environment is a set of deterministic codes such as FLOPS, NEPP/WATE, or ALCCA that are used to model the complete aircraft design and mission. These codes usually include calibration, or $k$ factors that are typically used as fudge factors, but for this study served as "technology dials". A series of custom made scripts were then used to take the $\mathrm{k}$ factors provided by the DoE and run the simulations as required by the DoE.

The results of these experiments are a table of results that include the inputs and responses for each case. After completing the simulation, the statistical package JMP is used to analyze these responses to create the RSE. Figure 10 shows the impact of each technology according to the RSE. Technologies are listed at the bottom (-1 is OFF and 1 is ON) and responses are listed at the ordinary axes.

\section{NEW DESIGN SPACE EXPLORATION}

Through the use of the exploration tools within JMP, the designer is able to examine the impact of any combination of inputs on any response. The independent effects of each technology are shown in Figure 10. This information allows the user to see quickly which technologies have the most positive effect on the design. In addition, it is also possible to check what effect the implementation of one technology has on the effects of other technologies.

In order to find the best technology combination that maximizes system desirability an intelligent decisionmaking process known as Technology Frontiers was used. If all thirteen of the evaluated technologies were compatible with each other, it would be necessary to 




Figure 10 - Independent Technology Effects

analyze more than eight thousand different technology combinations. The technology compatibility matrix, however, was used to disregard all incompatible cases, reducing the number of required evaluations to slightly over two thousand.

Some of the technologies that involve revolutionary materials like stitched composites only affect some parts of the aircraft, like wings or empennage, while other material technologies like the Russian Aluminum is intended to be used in the fuselage. This fact results in fewer incompatibilities. Another important incompatibility occurs between LPP and RQL; which occurs since both technologies use conflicting $\mathrm{NO}_{x}$ reduction strategies on the same component, the combustor.

\section{$\underline{\text { TECHNOLOGY FRONTIERS }}$}

Once all of the technology impacts are established, it is important to use a method that allows the designer to locate accurately the best solution and therefore the best technology combination that will enhance the performance and reduce the cost of the design. Three commonly used decision-making techniques are, Overall Evaluation Criterion (OEC), the Technique for Order of Preference by Similarity to Ideal Solution (TOPSIS) ${ }^{13}$, and the Technology Frontier Selection Method. The latter allows for a visual inspection of which technology combination best fits the customer needs as well as the trade between performance and cost. For more information on other methods refer to Ref. 13. By using this method, it is possible to spot the best solution by measuring the distance from each point to the required solution. Two important parameters are defined, the Performance Index and Economic Index that help to 
identify and trade between economic and performance costs. Each figure of merit (or response) is assigned a weight of importance. This weight of importance, generally imposed by customers, is used to determine the overall result of a particular technology combination. The formula below shows how the performance or economic efficiencies of each technology combination are calculated; notice that all responses are normalized with respect to the baseline.

$$
E f f=\alpha \cdot \frac{R_{1}}{B_{1}}+\beta \cdot \frac{R_{2}}{B_{2}}+\cdots
$$

Where $\alpha$ and $\beta$ are weights of importance, $R_{i}$ is the actual response, and $B_{i}$ is the baseline value of such response. Customer constraints are calculated by using this same formula and replacing responses with customer targets. Figure 11 illustrates all possible and compatible combinations of seven technologies. The normalized constraints represent the threshold of success. They are depicted by red lines and represent the customer requirements. Notice how the performance index decreases as the economic efficiency increases. The target space is on the upper right hand corner of the figure.

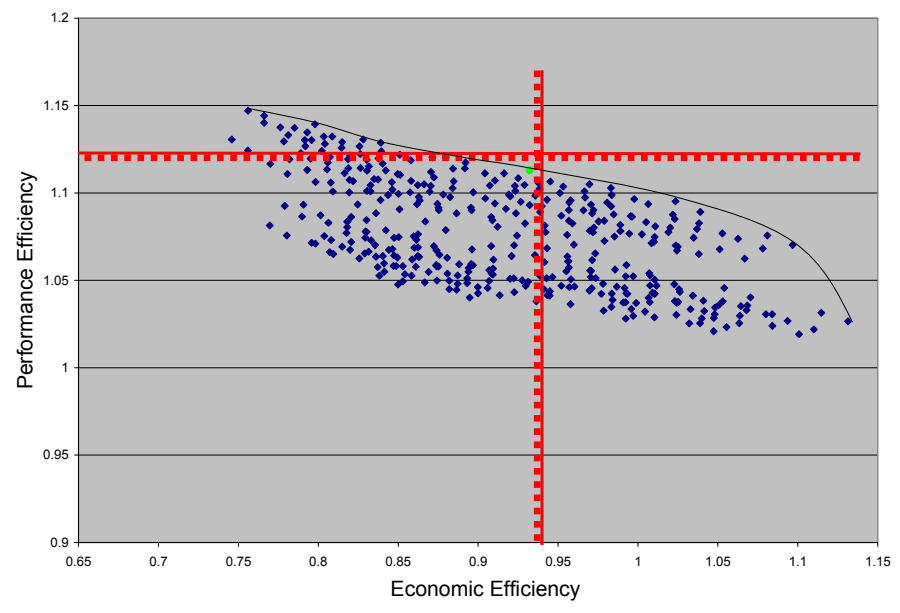

Figure 11 - 7 Technology Combinations

The solid line bounds the data points represents the technology frontier. This technology frontier allows the designer to easily visualize the limit achievable by any combination of a number of technologies (in this case 7 ). The technology frontier, shown on this graph, represents the limit of what the selected technologies can do to achieve the desired goals.

\section{TECHNOLOGY EVALUATION RESULTS}

The results obtained from this study show that six and seven technology combinations are the best options to consider, since their respective efficiencies approach the solution required to meet the targets. Once more, the customer will have to make a trade between performance and cost.

Table 4 shows the different technologies included in the best two solutions. Some of the technologies appear in both, meaning that to accomplish the targets established by the customer it is worth investing on these common technologies.

\begin{tabular}{|l|l|}
\hline T1 & Composite materials \\
\hline T5 & Circular flow and Boundary Layer Control \\
\hline T7 & LPP \\
\hline T8 & CMC \\
\hline T9 & LW Nozzle Materials \\
\hline T10 & Active Combustion Control \\
\hline
\end{tabular}

Table 4 - Best Six Technology Combination

\begin{tabular}{|l|l|}
\hline T3 & Superplastics \\
\hline T7 & LPP \\
\hline T8 & CMC \\
\hline T9 & L W Nozzle Materials \\
\hline T10 & Active Combustion Control \\
\hline T11 & Enviromental Engine \\
\hline T12 & Advanced Avionics Systems \\
\hline
\end{tabular}

Table 5 - Best Seven Technology Combination

\begin{tabular}{|l|c|c|c|}
\hline & 6 Techs. & 7 Techs. & Target \\
\hline TOGW (lbs) & 108392 & 99942 & 125,000 \\
\hline TOFL (ft) & 5632 & 5423 & 6,500 \\
\hline Vapp $($ knots) & 127 & 121 & 130 \\
\hline FONOISE $(\mathrm{dB})$ & 78.058 & 80.448 & 88.000 \\
\hline SLNOISE $(\mathrm{dB})$ & 88.664 & 86.566 & 92.000 \\
\hline NOx Red \% & $-48 \%$ & $-46 \%$ & $0 \%$ \\
\hline CO2 $(\mathrm{lb} / \mathrm{nm})$ & 36.63 & 32.20 & 50.00 \\
\hline Impulse $\left(\mathrm{lb}{ }^{*} / \mathrm{ft}^{2}\right)$ & 0.014 & 0.013 & 0.020 \\
\hline SBPRISE $(\mathrm{psf})$ & 0.678 & 0.667 & 0.500 \\
\hline Acq $(\$ M)$ & 129 & 131 & 100 \\
\hline DOC $(\$ / N M)$ & 8.30 & 8.28 & 6.00 \\
\hline
\end{tabular}

Table 6 - Best Options Results

\section{CONCLUDING REMARKS}

The goal of this research is to develop a multidisciplinary analysis environment in order to study the feasibility of a Supersonic Business Jet design based on the current and forecasted market conditions as well as the technology and resources available. This environment has been successfully created and used to evaluate the impact of the configuration, design mission, requirements, and technologies on a baseline system.

Through the use of this environment, it was determined that this baseline system, as identified within the Morphological Matrix, cannot meet sonic boom requirements for unrestricted overland flight, even with the infusion of up to seven advanced technologies.

The proper design approach for future work would be to continue searching for a feasible design by computing alternative solutions and exploring the design space around different concepts from the Morphological Matrix. 
The results of this study indicate that future technology studies relating to quiet supersonics should probably focus on structural technologies that enable advanced configurations such as joined or parasol wings to reduce sonic boom, since our literature search did not identify any realistic technologies directly affecting boom intensity. Other technologies that further reduce operation and maintenance costs would be attractive, as well. Finally, further market research is necessary to evaluate the willingness of customers to trade between system cost and performance.

\section{ACKNOWLEDGEMENTS}

The authors would like to thank the other members of the 2002 Graduate SBJ Design Team, Dr. Michelle Kirby, Dr. Jimmy Tai, and Mr. Rob McDonald for their assistance during this project.

\section{REFERENCES}

1. Myers, R.H., Montgomery, D.C., Response Surface Methodology: Process and Product Optimization Using Designed Experiments, John Wiley \& Sons Inc., 1995

2. McCullers L. A., "Flight Optimization System" NASA Langley Research Center, Hampton, VA, April 2001.

3. Carlson, H, Chu, J., Ozoroski, L., McCullers, L., "Guide to AERO2S and WINGDES Computer Codes for Prediction and Minimization of Drag Due to Lift," NASA TP-3637, 1997.

4. Klann J. L., Snyder C. A., "NASA Engine Performance Program" Aeropropulsion Analysis Office, NASA Lewis Research Center, Cleveland Ohio, March 1997.

5. Boeing Military Airplane Development, NASA-Glenn Research Center, PSAO office "Weight Analysis of Turbine Engine" 1979.

6. Garcia, E., Marx, W., Mavris, D. "ALCCA User Notes," Aerospace Systems Design Laboratory, Atlanta, GA.

7. Karal, Michael, AST Composite Wing Program Executive Summary, The Boeing Company, Long Beach, California, March 2001.

8. Dexter, Benson, H., Development of Textile Reinforced Composites for Aircraft Structures, NASA Langley Research Center, Proceedings of the fourth International Symposium for Textile Composites, Kyoto Institute of Technology, Kyoto, Japan, October 1998.

9. R. Keith Bird, Dennis L. Dicus, Evaluation of Pressurization Fatigue Life of 1441 Al-Li Fuselage Panel, NASA, Langley Research Center, Hampton Virginia, 1999.

10. Frank P., Tan Y., Griebel P., Nannen H., Eickhoff $H$., "Analysis of NO-Formation for Rich / Lean - Staged Combustion
11. DeLaat, J., Chang, C., Paxon, D, Saus, J., Le, D., "Active Combustion Control Technology", MITE Workshop on Goals and Technologies for Future Gas Turbines, Atlanta, GA, December of 2000

12. Woods, J.A, Pototzky, A.S, Sherwood, T.H, Active Load Control During Rolling Maneuvers, NASA Technical Paper 3455, 1994

13. Kirby, R. M., TIES for DUMMIES $2^{\text {nd }}$ Edition, Aerospace Systems Design Lab, Georgia Institute of Technology, February of 2001.

14. Mavris, D.N., Baker, A.P., "Assessing the Simultaneous Impact of Requirements, Vehicle Characteristics, and Technologies during Aircraft Design", 39th AIAA Aerospace Sciences Meeting and Exhibit, Seattle, WA, 2001.

15. Coen, Peter. "Development of a Computer Technique for the Prediction of Transport Aircraft Flight Profile Sonic Boom Signatures," Master's thesis, The George Washington University, 1991.

16. Carlson, H. W., Maglieri, D., "Review of Sonic-Boom theory and Prediction Methods," J. Acoust. Soc. America," vol. 51, no. 2, pt. 3, Nov. 1970, pp. 675684.

17. Haglund, G. T., "HSCT Designs for Reduced Sonic Boom", American Institute of Aeronautics and Astronautics, 1991.

18. Miranda, R. L., Elliott, D. R., Baker, M. W., "A Generalized Vortex Lattice Method for Subsonic and Supersonic Flow Applications". NASA CR-2865, 1977.

19. Harris, Roy V. Jr. "An Analysis Correlation of Aircraft Wave Drag" NASA TMX-947, March 1964.

20. Middleton, W. D., Lundry, J. L. "A System of Aerodynamic Design and Analysis of Supersonic Aircraft" NASA CR-3351, 1980.

21. Buonanno, M., Lim C., Mavris, D.N., "Impact of Configuration and Requirements on the Sonic Boom of a Quiet Supersonic Jet", SAE No. 02-WAC-121

22. Fernandez I., Krause A., Mavris, D.N., "Identification and Evaluation of Technologies for the Development of a Quiet Supersonic Business Jet" SAE 02-WAC-119

23. Briceno, S., Mavris, D.N., "Quiet Supersonic Jet Engine Performance Tradeoff Analysis Using a Response Surface Methodology Approach" SAE 02WAC-120

\section{CONTACT INFORMATION}

Simon I. Briceño

simon.briceno@asdl.gatech.edu

Michael A. Buonanno

michael.buonanno@asdl.gatech.edu

Ismael Fernández-Martín

ismaelf@asdl.gatech.edu

Dr. Dimitri N. Mavris

dimitri.mavris@aerospace.gatech.edu 


\section{APPENDIX}

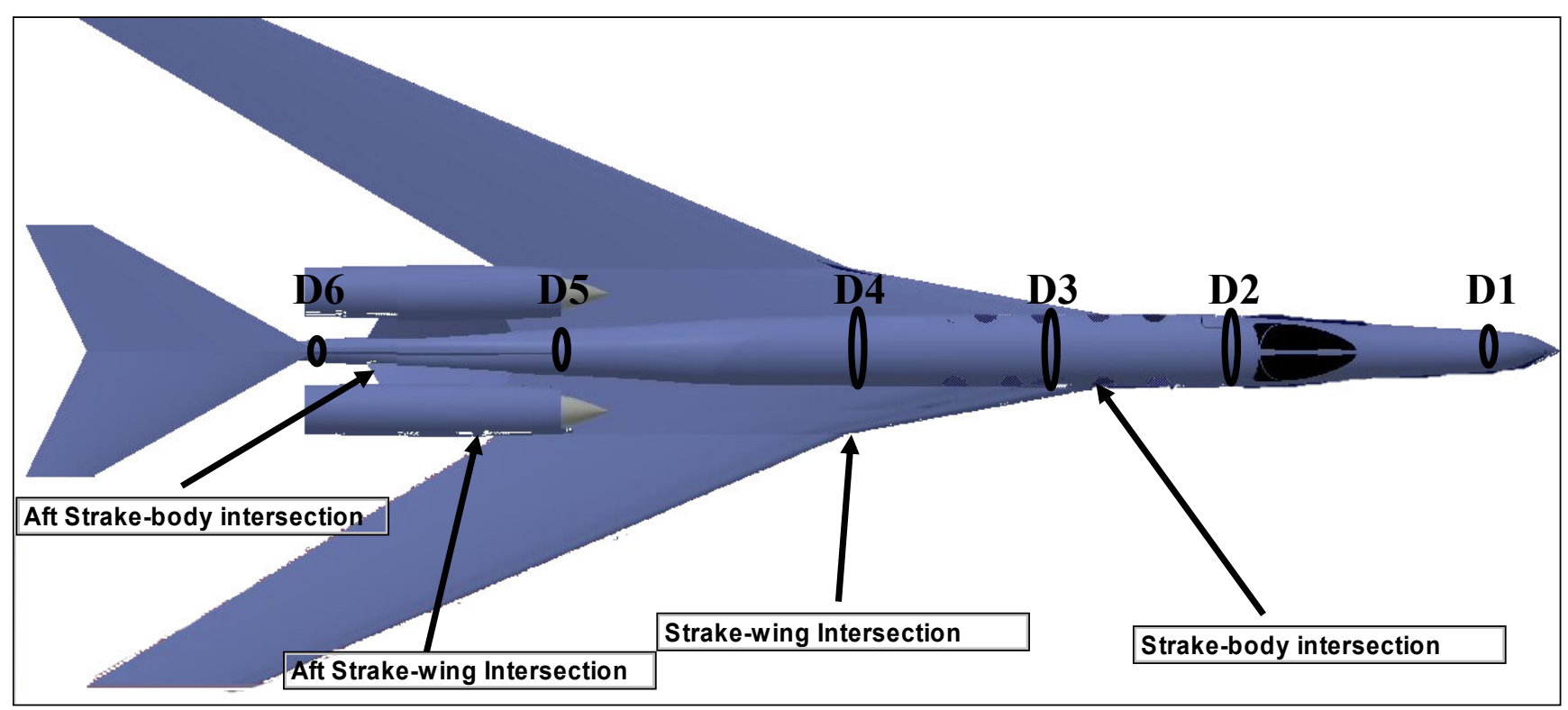

Figure 12 - Planform and Fuselage Design Variables

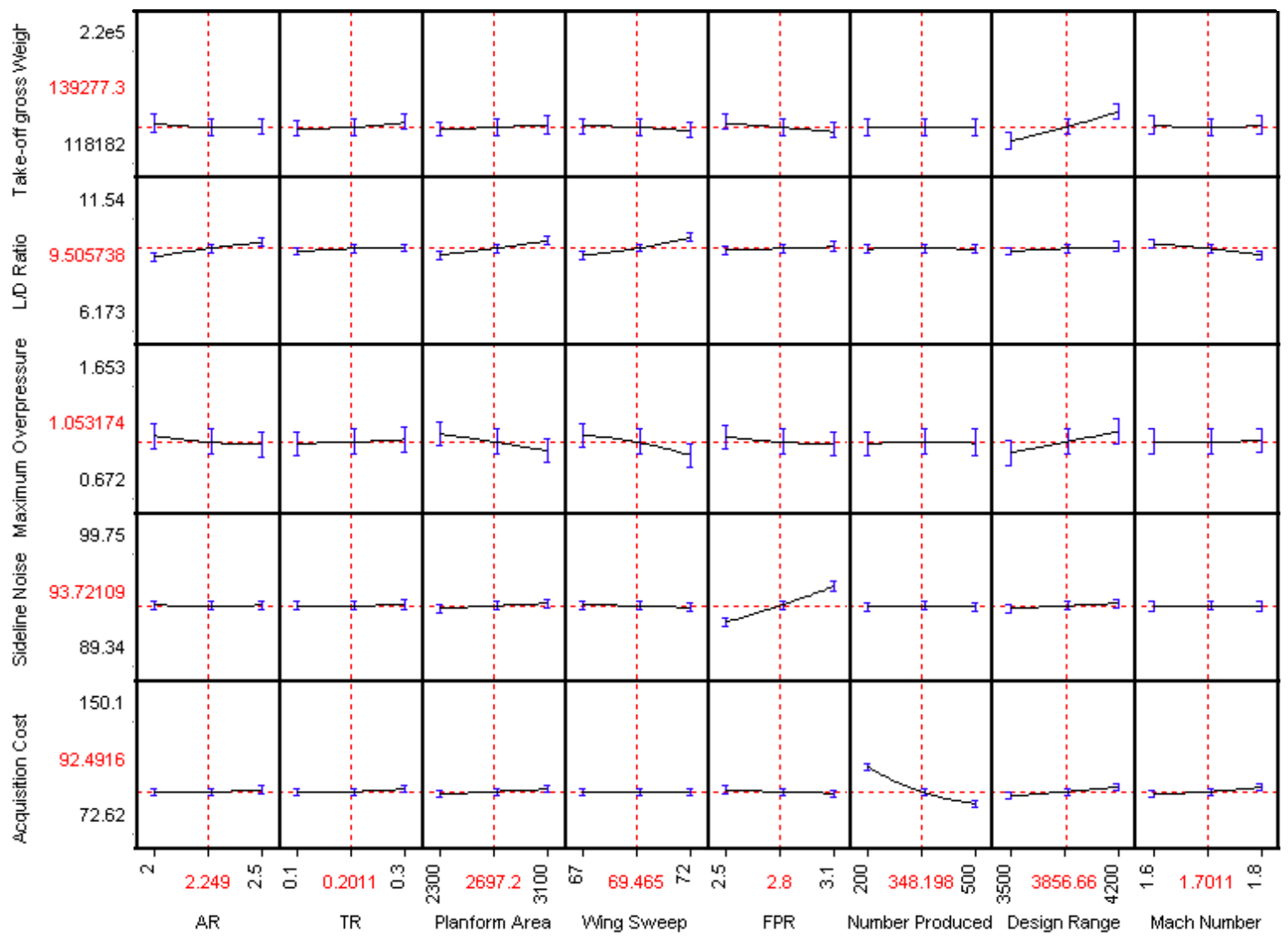

Figure 13 - Dynamic Tradeoff Environment 